\title{
FRANCESES NO BRASIL Séculos XIX - XX
}

\author{
Laurent Vidal e Tânia Regina de Luca (orgs.) \\ São Paulo: Ed. UNESP, 2009, 487p.
}

Os grandes eventos podem criar o ensejo para despertar a atenção para temas em princípio pouco conhecidos, como a existência de imigrantes franceses no Brasil. De fato, não é de se estranhar que alguém pergunte: houve uma imigração francesa para o Brasil? Para abordar essa questão, é mais do que oportuna a iniciativa da UNESP, por ocasião das celebrações do "Ano da França no Brasil", ao lançar um livro que pretende apresentar um amplo painel dos estudos históricos sobre a presença de franceses no Brasil ao longo do século XIX e início do XX. Ao lado deste marco comemorativo, que pretende realçar a importância da colaboração de imigrantes de origem francesa, como grupos ou individualmente, na construção da nação brasileira, o que se pretende é a exposição de diferentes estudos que se realizaram, ou estão em andamento, ou ainda que sugerem pistas novas de desenvolvimento, sobre os franceses no Brasil. O seu intuito inicial é mostrar que, para além da influência política e cultural marcante da França sobre a jovem nação brasileira, a presença real de imigrantes franceses, seja lá qual for a forma com que se pode defini-los, teve um peso fundamental no intercâmbio entre os dois países.

Considerando esse quadro, este livro, como uma coletânea de artigos, nos dá como primeira impressão uma imagem de um todo desigual, em que alguns trabalhos surgem como bem acabados, enquanto outros passam a sensação de que estão ainda avançando no andamento da pesquisa. Por outro lado, o todo do projeto inicialmente também parece um pouco improvisado, pois não se consegue facilmente identificar o que pode definir o que seria esta imigração francesa para o Brasil. A sensação de fragmentação, se de um lado pode vir justamente desse contexto de publicação e do fato de ser uma reunião de artigos de origens e motivações diferenciadas, por outro parece revelar o estado da arte nesse campo de estudos e o que realmente foi, historicamente, esse contato entre as duas nações, inclusive através da presença de cidadãos franceses no território brasileiro. Os organizadores da obra, no prefácio, parecem querer dar conta desses limites, salientando o objetivo principal que se busca alcançar: " $A$ 
proposta deste livro coletivo é justamente incentivar a formação de um campo de estudos sobre a presença dos imigrantes franceses no Brasil, tarefa que demanda a união de esforços de especialistas dos dois países". (p.17)

Nesse sentido, tendo em conta esses limites, um dos grandes méritos da publicação, como várias vezes é explicitado ao longo dos textos, é apontar para novas possibilidades de pesquisa ou sugerir novos enfoques para a compreensão da formação histórica brasileira. Acrescentaríamos também, do ponto de vista dos estudos sobre as migrações, que ela abre novas perspectivas para o estudo da história das migrações para o nosso país. A própria maneira como os textos foram distribuídos pelo volume já indica uma forma de classificação desses temas de estudo, embora talvez não seja a única possível, nem a mais interessante. A primeira parte, "Imigrar para o Brasil: imagens e realidade", traz textos que tentam fazer um levantamento sobre os possíveis significados atribuídos à imigração francesa no Brasil, além de um trabalho de descrição da população que imigrava do Porto de Bordeaux em direção ao Brasil. O texto mais interessante é aquele que trata da proibição, pelo Estado francês, da imigração contratada para o Brasil, de 1875 a 1908, e todo o esforço diplomático brasileiro na tentativa de levantar essa proibição.

A segunda parte, intitulada "Terra de refúgio e terra de utopia", trata do movimento individual ou coletivo de franceses que se deslocaram para o Brasil por motivações políticas, ideológicas, ou simplesmente na fuga de algum tipo de perseguição na terra de origem. O que se depreende é que existia uma verdadeira multiplicidade de motivos que poderiam levar grupos esparsos de franceses tentarem uma nova sorte num país recém-independente, oferecendo oportunidades desconhecidas para se reconstruir a vida. Na verdade, era a própria instabilidade social e política da França que levava esses grupos inquietos a se aventurarem fora do país. De um lado, houveram grupos de franceses que vieram ao Brasil por ocasião da queda de Napoleão Bonaparte, unidos ou não pelo mesmo ideal político, e que souberam aproveitar a grande carência de profissionais nas mais diversas áreas técnicas para fazer carreira no Brasil imperial. Por outro, temos um grupo de socialistas, seguidores de Fourier, que tentaram criar uma experiência de Falanstério em Saí, em Santa Catarina, e que fracassou desde os seus primórdios. Por fim, existe todo um grupo de judeus oriundos da Alsácia Lorena que, suportando uma condição de párias no país de origem, vindo ao Brasil, souberam aproveitar diversos ramos do comércio de luxo, sobretudo em cidades como o Rio de Janeiro. Mais do que outros, souberam usufruir da notoriedade da cultura francesa para intermediar o comércio de bens importados na capital do império e em outros centros urbanos.

A terceira parte justamente procura colocar em destaque a importância da inserção de grupos de imigrantes franceses na formação do espaço urbano em 
algumas das emergentes cidades brasileiras no século XIX: "O amplo leque das atividades urbanas". Essa inserção se apoiou fortemente numa "imagem de marca" da cultura francesa, associada à sofisticação, glamour, prestígio social, desenvolvendo a vida noturna e os prazeres da boemia. Assim, numa cidade como São Paulo, que estava saindo do ambiente colonial em que permanecera até então estagnada, e começando a se enriquecer com o ciclo do café, em seu centro instalava-se todo um comércio de moda francesa, apoiado em atividades ligadas à perfumaria, cabeleireiros, vestuário, etc. Na capital do Império, a vida noturna ganhou ares de sofisticação com a aparição de artistas e cocottes francesas, o que de certa forma maquiava a introdução da prostituição também no seu nível mais degradante, em que também eram maioria as mulheres europeias de diferentes origens, embora a imagem da prostituta "francesa" predominasse. Em Fortaleza, por outro lado, criaram-se as condições para o estabelecimento de uma grande rede de comércio de importação-exportação, em que se sobressaíam famílias francesas de origem judaica, como os "Boris Frères". A trajetória dessas famílias, o modo como souberam se aproveitar das condições da economia nordestina - a produção do algodão, a seca de 1878 , o financiamento político das elites locais - são um exemplo de como certas camadas da burguesia europeia se enriqueceram em torno do intercâmbio com países herdeiros do colonialismo europeu. Na Manaus que se enriquecia com o ciclo da borracha, a elite local se serviu abundantemente do imaginário de uma "Paris das selvas" para estruturar seu meio urbano e formar seu ambiente social, tanto através da cultura material como da vida literária e boêmia. Por fim, o pequeno, mas ativo grupo de franceses na cidade do Rio de Janeiro alimentava uma intensa vida associativa, em que se destacava uma imprensa que opinava sobre as questões europeias da época, mas também estava atenta à sociedade local.

A quarta parte volta-se para o lado talvez mais obscuro da imigração francesa para o Brasil, a dos poucos projetos de imigração contratada para colonização rural que chegaram a envolver grupos de franceses imigrados: "As experiências das colônias agrícolas". Com efeito, o fracasso desses projetos, a situação de precariedade em que muitos desses imigrantes retornaram à França, deve ter servido como principal justificativa para a proibição da imigração contratada para o Brasil alguns anos depois. As informações remanescentes dos projetos de colonização de "Valão dos Veados" (RJ) e de "Benevides" (PA) demonstram a distância entre a proposta dos empresários brasileiros que financiavam tais projetos com o apoio do governo imperial, e a realidade em que eles de fato vieram a se concretizar. Por outro lado, o exemplo do projeto de Carangola (MG), levado à frente pelo francês Alexandre Bréthel, serve de interessante contraponto ao modelo dos projetos da imigração contratada idealizados pela elite do Império brasileiro. 
A quinta parte, de certa maneira, explicita o caráter multifacetado já presente nas outras partes do livro, ao mesmo tempo em que demonstra outro modo de se entender os deslocamentos de franceses para o Brasil, ao confrontar trajetórias individuais com o contexto social e político mais amplo em que se inserem: "Trajetórias individuais e memória". Ao recuperar a passagem de algumas personalidades francesas marcantes por Minas Gerais, levantaram-se aspectos importantes da ocupação do território, sua exploração econômica, a pacificação de tribos indígenas e a formação de escolas de mineralogia. Ao retomar a figura de Auguste François-Marie Glaziou e suas relações com a elite da capital do Império, é a história do paisagismo do Rio de Janeiro, de seus parques e da remodelação de seu espaço urbano que se destaca. O capítulo sobre os livreiros Garnier no Rio de Janeiro, e Garraux em São Paulo, traz luzes sobre a formação cultural dessas cidades, ao mesmo tempo em que expõe os diferenciais de seu perfil socioeconômico, através da própria trajetória de vida desses dois imigrados. Porém, nada se compara com a extraordinária história de vida de Hercule Florence, seja como naturalista que participou da expedição Langsdorff ainda durante o I Império, em que descreveu e retratou em detalhes as várias regiões por que passou, seja pelas suas relações com as elites liberais da Província de São Paulo, desenvolvendo atividades como cientista, educador, humanista, na imprensa, na iconografia, em projetos de colonização rural. Por fim, recuperar essa memória fragmentária, entre a projeção de personalidades individuais e a inserção de grupos de imigrantes, sempre toma caminhos condicionados pela busca de afirmação identitária na atualidade, como a dos descendentes da colônia de Saí em Santa Catarina em fins do século XX.

A riqueza desse conteúdo, inclusive devido à sua heterogeneidade, pode também ser explorada por meio de outras perspectivas, abrindo para outras temáticas e sugerindo outras intuições sobre o significado dessa inserção de franceses na história brasileira. Do ponto de vista do estudo da história das migrações, numa leitura transversal, podem-se vislumbrar diferentes alternativas de compreensão da mobilidade humana em nosso país por meio de outros eixos de análise. O confronto, por exemplo, entre as razões de Estado que motivaram o Brasil em seus projetos de imigração contratada, com aquelas que conduziram a França em sua expansão colonial e comercial, pode ganhar uma nova luz quando consideramos a experiência vivida por esses diferentes grupos de franceses no Brasil do século XIX. O próprio estudo da grande imigração, para substituir o braço escravo ou ocupar o território das fronteiras agrícolas, pode ganhar outra percepção se comparado e inter-relacionado com esses fluxos segmentados de grupos e indivíduos de origem francesa aqui estudados. Se o estudo do processo decorrente da proibição, pelo governo francês em 1875, da imigração contratada para o Brasil, e os esforços contínuos do Brasil para reverter essa decisão trazem à tona as contradições inerentes aos intercâmbios 
entre os dois países, entre seu ideário e sua realidade política, não deixa de ser impressionante a influência que os franceses presentes no país exerceram na produção de um imaginário social, cultural e político que modelou a formação de nossa sociedade.

Entre as muitas leituras possíveis sobre a participação dos imigrantes no processo histórico da formação da sociedade brasileira no século XIX, as contribuições desse livro apontam para a importância do cotidiano vivido por esses imigrantes, e em particular, suas relações interculturais e o uso ideológico de um determinado imaginário sobre a "cultura francesa". Interessava às elites políticas de uma nação recém-independente e ainda escravocrata, a utilização desse imaginário para se fazer respeitar internacionalmente, pela ostentação de um padrão de vida "civilizado", que se refletiria em suas relações sociais, num espaço urbano e num estilo de consumo burguês. À França interessava o uso dessa "imagem de marca", não só para ampliar o mercado de seus produtos, mas também para estender sua influência econômica e política para além das fronteiras de seu império colonial. No entanto, também para os imigrantes franceses interessava esse reconhecimento da cultura francesa como padrão de civilização. Esse é um aspecto amplamente ressaltado em vários estudos reunidos neste livro. Foram os imigrantes que, localmente e no cotidiano de nossas cidades ainda provincianas, desenvolveram todo um arco de atividades comerciais e culturais que ajudaram a modelar o espaço urbano, imprimindo outros costumes e outras rotinas, além de despertar outras aspirações sociais. Eles souberam usar, inclusive como estratégia de sobrevivência, elementos materiais e ideológicos da cultura francesa para desenvolver o que se aspirava então como um padrão de vida burguês. Nesse sentido, embora reduzidos em número, esses franceses tiveram um papel decisivo na constituição histórica do cotidiano vivido pelos brasileiros.

Outro veio de análise pelo qual seria possível fazer uma leitura alternativa da experiência desses imigrantes no Brasil, encontra-se em suas relações interculturais, em outras palavras, no tipo de relacionamentos em que eles se apoiavam e mobilizavam em sua inserção no território brasileiro. Basta assinalar que, ao contrário dos projetos de imigração contratada, parece que os casos de inserção bem sucedida de imigrantes no meio rural foram intermediados por redes estabelecidas entre os próprios imigrantes franceses. Não se trata apenas do exemplo de Carangola, mas também de outras iniciativas como as de Hercule Florence ou Monlevade. Ou então, quando alguma personalidade francesa soube usufruir de um contato privilegiado com a elite brasileira, laços de confiança eram estabelecidos no emprego de recursos que o clientelismo político dispunha, favorecendo a ascensão social, como foi o caso de Jean Etienne Seraine, ou mesmo dos irmãos Boris. De resto, as redes estabelecidas pelos franceses, nas diferentes vertentes sociais e políticas, permitiram que 
eles tivessem uma importância decisiva na formação do espaço urbano de São Paulo e do Rio de Janeiro, ou na ocupação de um grande território, como foi a colonização da região do Rio Doce, em Minas Gerais.

Enfim, não há como deixar de ressaltar que um livro como esse, através de seus vários estudos de casos individuais, apresenta um horizonte amplo para a pesquisa sobre o cotidiano dos migrantes. Isso porque, diante das muitas lacunas dos registros oficiais, o uso abundante de fontes, como diários e cartas, favorece um olhar atento para suas representações e o modo como se davam as relações no dia a dia entre os estrangeiros e os povos nascidos no país. No caso dos imigrantes franceses, o uso frequente da escrita entre seus pares permite algo muitas vezes difícil, isto é, a recuperação da palavra do próprio migrante no interior dos processos históricos nos quais está envolvido. A alteridade do imigrante francês, no caso desses estudos, permite um olhar alternativo à visão hegemônica sobre a construção da nação brasileira, sobre o fenômeno migratório no século XIX e sobre os processos sociais e políticos que então se desenrolavam.

Sem dúvida, trata-se de uma grande contribuição ao estudo das migrações. Teríamos apenas que sinalizar para alguns equívocos com datas, como, por exemplo, aquele que aponta 1879 como o ano do centenário da queda da Bastilha (p.11). Nada que uma revisão mais atenta não pudesse corrigir ou que venha prejudicar o conjunto do trabalho. Ressalte-se que o livro tem uma apresentação muito bem acabada, cheia de ilustrações e que se deixa ler com prazer. Porém, acima de tudo, possui sua grande relevância na abertura de novos campos de pesquisa histórica, bem como na sugestão de novos olhares para o cotidiano dos migrantes. Nem que seja só por isso, o evento do "Ano da França no Brasil" terá valido a pena.

Por: Sidnei Marco Dornelas Centro de Estudos Migratórios 